\title{
Constraints in Spoken Proficiency: Causes and Remedial Measures
}

\author{
Shantha Sambath a * D, Mekala Sethuraman a \\ a National Institute of Technology, Humanities and Social Sciences, India
}

Received 13 December 2016 | Received in revised form 17 August 2017 | Accepted 20 September 2017

\begin{abstract}
Spoken proficiency in English has become indispensable in engineering industry. It is expected of an engineering student to possess requisite spoken proficiency for his/her career growth prospects. The paper focuses on the impediments in the speaking skills of the engineering students and also finds the ways to improve students' speaking skills using task-based pedagogical design. The article further investigates the factors that affect the speaking performance of the ESL learners. This article explores the pivotal role played by the pedagogical intervention in the classroom in enabling the learners to overcome the constraints in speaking. The participants of the study chosen for control and experimental group were first year civil engineering students comprising 38 in each group respectively. T-test was used to compare the performance of the students in control and experiment groups. The cross tabulation was also computed to know the scoring pattern of the spoken components in the assigned tasks. The results revealed that there was a significant level of improvement in the oral proficiency of the experimental group.
\end{abstract}

Keywords: Affective factors; engineering students; oral communicative tasks; speaking constraints; spoken proficiency.

\section{Introduction}

English language and communication skills have become a mandatory requisite in today's globalised world. Particularly they are essential for an engineer who aspires to be successful in his/her profession and the major pre-condition for an engineering student is to be a fluent speaker in conveying his/her thought process. An engineer needs oral proficiency in English to make presentations, conduct meetings, give instructions, and participate in discussions in his/her work place environment. The inadequacy in English speaking skill refrains the engineering graduates from getting job placements. Basically, most of the students study English for approximately 12 years before entering the tertiary level; nevertheless, they lack spoken proficiency in English. Many students entering engineering colleges have little training in speaking skills despite years of learning English during school. More emphasis could be laid on improving the spoken proficiency of students within the curriculum at the tertiary level as the primary objective for any higher learning institutions is to produce

\footnotetext{
* Shantha Sambath.

E-mail address: shantha.ravi39@gmail.com

http://dx.doi.org/.......
} 
employable graduates. The researcher of the study is an English teacher, who considers that it is necessary to develop the speaking skills of the engineering students for their academic excellence and career prospects. With this regard, this study focuses on constraints faced by the engineering students while speaking English and also manages to find a way to improve students' speaking skills using task-based teaching approach. It further explores teacher's perceptions of the problems students encounter while speaking English and the crucial role played by the pedagogical intervention in helping the learners to develop their speaking skills. It is expected that the outcomes of the study would enhance the development of the participants' speaking performance and also provide more insight for teachers to intervene into alternative activities to develop speaking skills for ESL learners in engineering context.

\section{Review of Literature}

This part covers three main aspects: significance of speaking, constraints in speaking for ESL speakers, and a task-based learning approach.

\subsection{Significance of speaking}

Speaking English is considered as the main goal of many learners as it is the significant skill they need to acquire, and they assess their progress in terms of their proficiency attainment. According to Bygate (1987) the learners of a language are judged by this skill. Speaking is a crucial part of language learning and teaching. Nunan (1991a) wrote, "Success is measured in terms of the ability to carry out a conversation in the (target) language" (p-34). McDonough and Shaw (as cited in Jamila, 2013) indicate that a person may often be judged about his/ her language competence from his/ her speaking rather than from any of the other language skills. Reimer (2007) states that the engineering students are required to acquire a range of skills, in which speaking skills in English is a vital component to meet the expectation of academia and industry. Zaremba (2006) indicates that speaking skills are usually placed ahead of work experience, motivation, and academic credentials as criteria for new recruitment for employment. Harmer (2007) states three main reasons for getting students to speak in the classroom: firstly, speaking activities provide rehearsal opportunities; secondly, speaking tasks provide feedback for both teacher and students and finally they provide opportunities to the students to activate various elements of language they have stored in their repertoire. A regular speaking task in the classroom can improve students' spoken proficiency. It requires teachers and students to be engaged in oral communicative tasks in real life situations. At tertiary level students require a range of speaking tasks that encourage a great degree of independence by relying on considerable oral practice mainly in the form of classroom interactions. The speaking tasks presented below take into account the above assumptions.

\subsection{Impediments in speaking}


Teaching speaking skills has always been a challenging task for most of the teachers in ESL context. The prime reason behind this lapse is lack of exposure to English speaking environment. Learners rarely use English for conversations among peers. Given a situation of this kind, students are not able to convey their thoughts fluently in second language as in their mother tongue. According to Horwitz, Horwitz and Cope (1986), speaking in a second language creates a "mental blocke as it is always considered as problematic by majority of students. Ur (1995) lists that commonly observed factors that affect learners' speaking in language classroom are 'inhibition', 'nothing to say', 'low or uneven participation' and 'mother-tongue use'. Horwitz et al. (1986) note that anxiety related to learning in a foreign language can be classified into three primary components: communication apprehension, fear of negative evaluation, and test anxiety. Nunan (1999) and Thornby (2005) argue that psychological factors such as anxiety or shyness, lack of confidence, lack of motivation and fear of making mistakes hinder students from speaking. Liu and Jackson (2009) claim that lack of vocabulary was regarded as a main obstacle for spoken communication by Chinese English learners. Juhana (2012) states three kinds of linguistic factors that affect the learners' speaking skills are lack of vocabulary, lack of knowledge in grammar and incorrect pronunciation. In line with these issues, Shanmugasundaram (2013) in his research has broadly categorized the factors which hinder the students in performing speaking as psychological, such as inferiority complex, lack of motivation, fear, shyness etc; sociological, such as their living environment, parents' educational level and employment status etc; linguistic, such as their poor knowledge of grammar, limited vocabulary, lack of fluency, L1 interference etc; and pedagogic, such as teaching and learning method followed in their schools and colleges, absence of role models etc.. He substantiated how these factors have affected the students of Government and Private Arts and Science colleges. A similar kind of situation prevails in engineering scenario in the context of second language learning.

\subsection{Speaking in L2-A task - based approach}

In recent years, numerous researchers in language teaching have explored TaskBased Language Teaching (TBLT) approach (Ellis, 2003; Long \& Crookes, 1992; Nunan, 1988; Prabhu, 1987). The TBLT approach implies that if learners are provided with a series of tasks that involve both comprehension and production of language with a focus on meaning, language development is increased. TBLT has proved itself useful in meeting learners' needs and in providing lots of interaction opportunities in ESL classes. Nunan (1991b) highlights five features of task-based approach as follows;

- An emphasis on learning to communicate through interaction in the target language

- The introduction of authentic texts into the learning situation 
- The provision of opportunities for learners to focus, not only on language, but also on the learning process itself

- An enhancement of the learner's own personal experiences as important contributing elements to classroom learning

- An attempt to link classroom language learning with language activation outside the classroom (p. 279).

In TBLT, tasks are the factors which are planned for the desired outcome in pedagogical intervention. Norris and Richards \& Schmidt (as cited in Van Le, 2014) have emphasized that TBLT integrates theoretical and empirical foundations for good pedagogy with a focus on tangible learning outcomes in the form of tasks, and therefore, tasks are considered as the core unit of planning and instruction in language teaching. Besides, TBLT is an effective approach where speaking skills are developed by performing a series of activities as steps towards successful task completion. Tasks function as "devices for creating the conditions required for language acquisition" (Ellis, 2002, p. 226). The classroom can be an effective and congenial environment to administer oral communicative tasks for improving the English speaking abilities of the learners. Consequently, this is bound to overcome the factors that affect speaking skills of the SL learners.

\section{Research rationale}

In the engineering curriculum, prescribed by Anna University the students are offered two papers on Technical English-I and II in their first and second semesters. One of the objectives of the papers is to develop the students' basic communication skills in English, with reference to the development of speaking skills. But priority is given for teaching other objectives such as grammar, vocabulary, writing skills for convenient reasons. In Technical English classes, the engineering students are seldom given opportunities to practice speaking, and speaking activities are not included as part of assessment in the end semester exam. Teachers consider spoken assessment as a laborious exercise, for they need to assess 60 students in the short schedule allocated to them. The students' inadequacy in spoken English is due to various reasons such as their regional medium of schooling, rural background, inadequate practice in speaking, fear of making mistakes, discouragement by peers, curriculum, teaching and assessment methodologies, less exposure to English speaking environment in academia and home, etc. Due to this negligence, numerous engineering students are passing out of the colleges and universities every year without acquiring the requisite speaking skills which are essential to the graduates for their career. The general employability of engineering students are affected by their lack of speaking skills. They are not able to perform well in their interview and lose their career opportunities. The Times Of India article on National Employability Report revealed the fact on Engineering Graduates of 2014 that $18.33 \%$ of the engineers were employable and $18.09 \%$ actually got a job. The article stated that 1.2 lakhs candidates were surveyed across the country, in which $73.63 \%$ lacked English 
speaking and comprehension skill ("Only 18\% engineering grads", 2014). The importance of this skill is felt only when they are called for an interview. For this reason, to secure a job they approach English speaking centers where most of the time is spent only for grammar. Hence there is a need to improve the speaking skills of these students during their undergraduate programme.

\section{Research Questions}

Keeping the aforementioned issues in mind, the researcher aims to answer the following research questions.

1. What are the constraints of ESL learners in speaking English in L2 context?

2. What are the factors that affect speaking skills of ESL learners?

3. What is the role of pedagogical intervention in improving spoken proficiency of the learners?

4. How the oral communicative tasks (OCT) enabled the learners to attain improvement in their speaking skill?

Details regarding how the questions are answered are provided below.

\section{Methodology}

\subsection{Participants}

The participants are first year B.E. students of Civil Engineering at M.A.M College of Engineering and Technology, Tiruchirapalli. The participants $(\mathrm{N}=76)$ were selected based on simple random sampling in which the samples were assigned to the control and experimental groups using lottery method (Kothari, 2004). The control and experimental groups consist of 38 students in each, and their ages range between 17 and 19 years. The participants comprise 22 females and 54 males. Most of them are from the same background with regard to their first language, previous educational experience and learning context. Even though the participants studied English for around twelve years, they were lacking speaking skill in English. Besides, proficiency level of the students ranged from below average to good in their school final mark sheet. Hence providing this kind of training is supposed to develop their speaking proficiency.

\subsection{Tools used in the study}

\subsubsection{Oral communicative tasks}

The oral communicative tasks are the primary instruments. Ellis (2003) states that tasks are tools for providing opportunities for learners to use the target language. For this reason, oral communicative tasks, which are the primary instruments, were designed to develop the students' speaking ability and also to enable them to think and generate sentences on their own. Table below shows how the oral communicative tasks were used in the study (see Table 1). 
Table 1. Oral communicative tasks.

\begin{tabular}{|c|c|c|}
\hline Schedule & Name of task & Task type \\
\hline \multirow[t]{3}{*}{ Day1 \&Day2 } & Ice Breakers & Pair \\
\hline & $\begin{array}{l}\text { Activity-1:- Point out the imaginative uses of the following things in } 3 \text { minutes. } \\
\text { A) Shoe lace, B) ruler, C) newspaper, D) pencil. }\end{array}$ & \\
\hline & $\begin{array}{l}\text { Activity-2 :-Make as many words as possible from the phrase 'SOLVING } \\
\text { PROBLEMS' in } 3 \text { minutes. }\end{array}$ & \\
\hline Day3\& Day4 & Pre-task $\quad$ Self-Introduction & Individual \\
\hline Day5\& Day6 & $\begin{array}{l}\text { Initial task. Listing } 10 \text { activities of given professions:- Doctor, Teacher, mechanic, } \\
\text { Cashier, Farmer, Beautician }\end{array}$ & Pair \\
\hline Day7\& Day8 & $\begin{array}{l}\text { Initial task Listing of five to do's :- To save money, To lose weight, To lead a } \\
\text { healthy life, to score marks, To be a good citizen. }\end{array}$ & Group \\
\hline Day9\&Day10 & $\begin{array}{l}\text { Initial task. Mentioning associated ideas on a topic:- Gold, Freedom, Dream, } \\
\text { Mobile, Cinema, Fast food, Hobbies }\end{array}$ & Pair \\
\hline Day11\&Day12 & $\begin{array}{l}\text { Initial task. Situation-based responses:- A)Apologize for coming late to the class. } \\
\text { B) Make an excuse for not submitting the assignment on time. C) Request your } \\
\text { librarian to issue you a new library card. D) Interrupt your friends who are in a } \\
\text { discussion and ask them to accompany you to the office. }\end{array}$ & Individual \\
\hline Day13\&Day14 & $\begin{array}{l}\text { Core task. Long answer interview:- A) Can you describe your early schooldays? } \\
\text { B) Can you describe your village/ home town/ native place? C) Can you narrate } \\
\text { any funny incident/ horrible/ embarrassing incident that happened in your life? }\end{array}$ & Pair \\
\hline Day15\&Day16 & $\begin{array}{l}\text { Core task. Discussing similarities \& differences:- Human Vs Computer, } \\
\text { Television Vs Newspaper, School life Vs College life, Laptop Vs I-pad, Classroom } \\
\text { learning Vs E-learning. }\end{array}$ & Group \\
\hline Day17\&Day18 & $\begin{array}{l}\text { Core task. Story completion - A young girl is alone at home, reading a horror novel, } \\
\text { there was a heavy storm outside, and she heard tapping sound coming from her } \\
\text { door....... }\end{array}$ & Group \\
\hline Day19\&Day20 & $\begin{array}{l}\text { Core task. Role-play Neighbourhood complaint } \\
\text { In a shop -attending a customer } \\
\text { The mismatched roommates } \\
\text { Interviewing a celebrity. } \\
\text { A fresher and a senior student at the college }\end{array}$ & Pair \\
\hline Day21\&Day22 & $\begin{array}{l}\text { Core task. Group discussion } \\
\text { Who influence you the most- parents, friends, or teachers? } \\
\text { What do you prefer- Govt. job, private job, business? } \\
\text { Hard work or smart work- which is important? } \\
\text { Democracy is hampering India's progress. } \\
\text { Films are corrupting the Indian youth. } \\
\text { Effects of online social networks on youth. }\end{array}$ & Group \\
\hline Day23\&Day24 & Post-task. Impromptu speech:- The best gift I have ever received & Individual \\
\hline $\begin{array}{l}\text { Beginning of } \\
\text { every class }\end{array}$ & $\begin{array}{l}\text { Supporting task. Short answer sessions:- } \\
\text {-Where do you come from? } \\
\text { - What are your favourite dishes? } \\
\text { - Which movie have you watched recently? } \\
\text { - What book have you read recently? } \\
\text { - Do you do a part time job? } \\
\text { - Where do you like to go on vacation? } \\
\text {-Do you associate yourself with any of the social networks? }\end{array}$ & Individual \\
\hline
\end{tabular}




\subsubsection{Questionnaire}

A pre-study questionnaire was administered to elicit details regarding the participants' profile. Besides, a post-study questionnaire was used to collect feedback from the participants upon the implementation of the oral communicative tasks.

\subsubsection{Observation sheet}

The observation sheet was used to note down the students' performance of the tasks - their ability to perform the task, their choice of diction, their sentence construction, coherence in their utterance, and correct pronunciation of words. At the end of each task completion the data from the observation sheet were transferred to the scoring sheet which includes assessing parameters - the task performance was scored as per the analytical rubrics specified in the Common European Framework of Reference (CEFR).

\subsection{Scoring rubrics}

The pre- and post-tasks and the task performances were assessed using the analytic parameters of spoken language scoring indicated by the Council of Europe (2001) in the CEFR. It includes the assessing parameters such as fluency, grammar, idea, volume and pronunciation. The assessment criteria and weightage of marks are tabulated.

Table 2. CEFR Speaking Assessment Criteria

\begin{tabular}{lc}
\hline Components Tested & Weightage of marks \\
\hline Fluency \& coherence & 4 marks \\
Grammatical Acceptability & 2 marks \\
Ability to expand the Idea & 1 mark \\
Volume & 2 marks \\
Pronunciation & 1 mark \\
Maximum Score & 10 marks \\
\hline
\end{tabular}

\subsection{Implementation}

In this experimental study, a schedule of 24 classes with 50 minutes spread over a period of 12 weeks was conducted to develop speaking proficiency of the learners. At the outset, the experimental group was given a general idea about the importance of developing speaking skills and to be fluent in English language as prospective engineers. They were also given general idea about the OCT sessions and its significance. Self- Introduction was administered to the control and experimental groups, as a pre-task to note their entry level. In Self Introduction, almost all the students participated enthusiastically in the experimental group. The control group also performed well in the pre-task as it was an opportunity to acquaint with others, and they came forward to perform with curiosity. The oral communicative tasks were administered to the experimental group. The tasks were assigned in a graded structure, and this sequencing of tasks enabled the students to perform voluntarily. 
However, Technical English (Code: H6152) course was handled to the control and experimental groups as a part of the main stream syllabus prescribed by Anna University. Though the course content deals with modules on Listening, Speaking, Reading and Writing skills (LSRW), the teachers give significance to grammar and technical content. This course content was followed for the control group students. In addition, the experimental group was facilitated with OCT sessions, to improve their speaking proficiency. Subsequently, two ice breaker sessions were handled to the experimental group at the beginning of the OCT to prepare the learners to take part in the tasks actively.

The list of administered OCT is comprehensively discussed in this section (see Table 1). In initial task (see Day 5 \&Day 6), the students were expected to list out the activities with reference to the given professions in words and phrases. The next task (see Day $7 \&$ 8) was done as group task. In the third task on mentioning five associated ideas on Facebook, dream, etc., the learners seemed to be more confident and were not concerned about their friends' negative evaluation. They corrected their mistakes from teacher's feedback. In fourth task on situation based responses most of the students used general terms such as 'sorry', 'congrats', 'excuse me', etc. Only a few responded appropriately. Furthermore, the learners showed interest in long answer interview and participated with excitement, despite their speaking constraints. Their anxiety level reduced substantially in due course. Peer pressure and teacher's motivation influenced the slow learners to interact in the class. In the sixth task on discussing the similarities and differences, the students made a sincere attempt, and many students showed steady improvement in delivering a coherent content. The duration of interaction also duly increased over time. This task turned out to be interactive, and the students voluntarily contributed, as in the case of previous task. The seventh task on Story Completion elicited instantaneous interaction and girls interacted well. In the subsequent task on Role- play, though the students had a few grammatical errors, they were able to enact their roles skillfully. Pauses and fillers reduced considerably. There was maximum participation in the following ninth task on Group Discussion. The initiators of Group Discussion had an influence on reluctant performers. The post-task on Impromptu Speech was administered to both the control and experimental groups to perceive the difference in attainment of spoken proficiency. During the final task on Impromptu speech, there was a substantial improvement in the experimental group. The post-task was assigned to the control group, and they felt reluctant. They were not able to perform the tasks, as they were not exposed to the nuances of content generation and delivery mechanism of speaking skill and strategic implication of oral communicative tasks.

\section{Data analysis and findings}

The focus of the study was to examine whether TBLT approach has a positive effect on first year civil engineering students with respect to their speaking proficiency. The quantitative analyses were computed using the Statistical Package for the Social 
Sciences (SPSS 17). The qualitative data were interpreted from the observation sheets noted during the implementation of OCTs, in pre and post-tasks.

\subsection{Independent sample t-test for spoken components in pre-task}

Independent sample t-test was run to compare the mean scores of each speaking component in the pre-task scores of the control and the experimental groups. The mean and standard deviation of the scores of the participants $(\mathrm{N}=76)$ are tabulated in Table 3.

Table 3. Independent samples t-test for spoken components in pre-task

\begin{tabular}{lllllll}
\hline Test Component & Group & $\mathrm{N}$ & $\mathrm{M}$ & $\mathrm{S} . \mathrm{D}$ & $\mathrm{T}$ Value & $\mathrm{P}$ \\
\hline Fluency & Experimental & 38 & 1.38 & 0.54 & 0.48 & 0.63 \\
& Control & 38 & 1.32 & 0.65 & & \\
Grammar & Experimental & 38 & 0.59 & 0.20 & 3.56 & 0.01 \\
& Control & 38 & 0.45 & 0.16 & & \\
Idea/Content & Experimental & 38 & 0.54 & 0.24 & 1.21 & 0.23 \\
\multirow{2}{*}{ Volume } & Control & 38 & 0.47 & 0.23 & & \\
& Experimental & 38 & 0.76 & 0.25 & 4.83 & 0.01 \\
Pronunciation & Control & 38 & 0.49 & 0.25 & & 0.01 \\
& Experimental & 38 & 0.61 & 0.21 & 3.76 & \\
Total & Control & 38 & 0.45 & 0.16 & & 0.01 \\
& Experimental & 38 & 3.91 & 1.01 & 2.81 & \\
\hline
\end{tabular}

${ }^{*} \mathrm{M}=$ Mean, ${ }^{* *} \mathrm{SD}=$ Standard Deviation

The above table reveals that there is no significant difference observed between the control and experimental groups in terms of fluency and idea/content in the pre-task score. They were not able to generate idea in the initial stage, as they were lacking in content. There is a significant difference between the groups in terms of grammatical ability, volume, pronunciation and total score $(p<0.01)$. The reason for this difference might be the reluctance of the control group in performing the pre-task. Moreover volume, pronunciation and grammar are considered as subsidiary parameters compared to the main scoring parameters such as fluency and content generation.

\subsection{Cross tabulation}

Cross tabulation was computed and tabulated to interpret the students' scoring pattern of speaking components in tasks. As seen, it gives a clear idea on their scoring pattern. 
Table 4. Cross tabulation of speaking component-Fluency in tasks

\begin{tabular}{llllllllll}
\hline $\begin{array}{l}\text { Score range } \\
\text { in Fluency }\end{array}$ & 1 & 2 & 3 & 4 & 5 & 6 & 7 & 8 & 9 \\
\hline 0 & 22 & 10 & 8 & 5 & 5 & 5 & 26 & 14 & 4 \\
0.5 & 0 & 0 & 0 & 1 & 0 & 1 & 0 & 0 & 0 \\
1 & 6 & 11 & 9 & 14 & 7 & 4 & 0 & 0 & 2 \\
1.5 & 2 & 5 & 5 & 5 & 11 & 6 & 0 & 1 & 3 \\
2 & 6 & 9 & 13 & 12 & 13 & 14 & 4 & 7 & 5 \\
2.5 & 2 & 3 & 3 & 1 & 2 & 6 & 6 & 9 & 13 \\
3 & 0 & 0 & 0 & 0 & 0 & 2 & 2 & 6 & 6 \\
3.5 & 0 & 0 & 0 & 0 & 0 & 0 & 0 & 1 & 4 \\
4 & 0 & 0 & 0 & 0 & 0 & 0 & 0 & 0 & 1 \\
Total no of & 38 & 38 & 38 & 38 & 38 & 38 & 38 & 38 & 38 \\
respondents & & & & & & & & & \\
\hline
\end{tabular}

Table 4 shows the students' scoring range in fluency. In the first task on SelfIntroduction 22 students scored 0 out of 4 . In the consequent tasks their scoring improved, except in task7 on Story completion. In that task, 26 students scored 0, as the learners were not able to be creative in composing a story, and their level of participation comparatively reduced.

Table 5. Cross tabulation of speaking component-Grammar in tasks

\begin{tabular}{llllllllll}
\hline $\begin{array}{l}\text { Score range } \\
\text { in grammar }\end{array}$ & $\begin{array}{l}\text { Tasks } \\
\mathbf{1}\end{array}$ & $\mathbf{2}$ & $\mathbf{3}$ & $\mathbf{4}$ & $\mathbf{5}$ & $\mathbf{6}$ & $\mathbf{7}$ & $\mathbf{8}$ & $\mathbf{9}$ \\
\hline 0 & 22 & 11 & 8 & 5 & 5 & 5 & 26 & 14 & 4 \\
0.5 & 10 & 16 & 22 & 25 & 24 & 18 & 9 & 1 & 12 \\
1 & 6 & 11 & 8 & 8 & 9 & 14 & 3 & 22 & 19 \\
1.5 & 0 & 0 & 0 & 0 & 0 & 1 & 0 & 1 & 3 \\
Total no of & 38 & 38 & 38 & 38 & 38 & 38 & 38 & 38 & 38 \\
respondents & & & & & & & & & \\
\hline
\end{tabular}

Table 5 shows the students' range of scores with respect to the grammar aspect in tasks. It is generally observed that the students made grammatical mistakes in the initial stage which is evident from considerable number of students securing 0 in the first task. Subsequently they were able to correct their errors, and mistakes substantially reduced in the last set of tasks. 
Table 6. Cross tabulation of speaking component-Idea/ content in tasks

\begin{tabular}{|c|c|c|c|c|c|c|c|c|c|}
\hline \multirow{2}{*}{$\begin{array}{l}\text { Score range } \\
\text { in content }\end{array}$} & \multicolumn{9}{|c|}{ Tasks } \\
\hline & 1 & 2 & 3 & 4 & 5 & 6 & 7 & 8 & 9 \\
\hline 0 & 25 & 11 & 10 & 8 & 6 & 7 & 26 & 14 & 4 \\
\hline 0.5 & 12 & 21 & 23 & 26 & 26 & 24 & 9 & 6 & 20 \\
\hline 1 & 1 & 6 & 5 & 6 & 6 & 7 & 3 & 18 & 14 \\
\hline $\begin{array}{l}\text { Total no of } \\
\text { respondents }\end{array}$ & 38 & 38 & 38 & 38 & 38 & 38 & 38 & 38 & 38 \\
\hline
\end{tabular}

Table 6 denotes the students' scoring range secured with reference to generating idea/content in tasks. In the early stage the students were lacking in content and were not able to generate ideas in the initial stage. Eventually they developed in generating ideas. Their scoring in content also gradually improved.

Table7. Cross tabulation of speaking component- volume in tasks

\begin{tabular}{|c|c|c|c|c|c|c|c|c|c|}
\hline \multirow{2}{*}{$\begin{array}{l}\text { Score range } \\
\text { in Volume }\end{array}$} & \multicolumn{9}{|c|}{ Tasks } \\
\hline & 1 & 2 & 3 & 4 & 5 & 6 & 7 & 8 & 9 \\
\hline 0 & 22 & 10 & 8 & 5 & 6 & 5 & 25 & 14 & 4 \\
\hline 0.5 & 7 & 14 & 12 & 15 & 14 & 14 & 4 & 7 & 12 \\
\hline 1 & 9 & 14 & 18 & 18 & 18 & 19 & 9 & 17 & 21 \\
\hline 1.5 & 0 & 0 & 0 & 0 & 0 & 0 & 0 & 0 & 1 \\
\hline $\begin{array}{l}\text { Total no of } \\
\text { respondents }\end{array}$ & 38 & 38 & 38 & 38 & 38 & 38 & 38 & 38 & 38 \\
\hline
\end{tabular}

Table7 shows the students' scoring pattern with respect to volume in tasks. 22 students scored 0 out of 2 in the first task. Later they gained confidence, and their voice level duly improved after making conscious efforts. They seemed to be slightly uncomfortable with task 7and task 8 on story completion and role- play respectively. Their diffidence in performance was reflecting in their volume.

Table 8. Cross tabulation of speaking component- pronunciation in tasks

\begin{tabular}{|c|c|c|c|c|c|c|c|c|c|}
\hline \multirow{2}{*}{$\begin{array}{l}\text { Score range in } \\
\text { pronunciation }\end{array}$} & \multicolumn{9}{|c|}{ Tasks } \\
\hline & 1 & 2 & 3 & 4 & 5 & 6 & 7 & 8 & 9 \\
\hline 0 & 22 & 10 & 8 & 5 & 5 & 5 & 25 & 14 & 4 \\
\hline 0.5 & 12 & 22 & 23 & 25 & 26 & 25 & 10 & 18 & 26 \\
\hline 1 & 4 & 6 & 7 & 8 & 7 & 8 & 3 & 6 & 8 \\
\hline $\begin{array}{l}\text { Total no of } \\
\text { respondents }\end{array}$ & 38 & 38 & 38 & 38 & 38 & 38 & 38 & 38 & 38 \\
\hline
\end{tabular}

Table 8 displays the students' scoring range with reference to pronunciation in tasks. Similar to other speaking components, 22 students scored 0 in the first task. In the due course their pronunciation improved in the subsequent tasks except tasks 7 and 8 . Hence it is inferred that the scoring pattern of the spoken components are 
interrelated within its aspects, and it is reflected in the overall oral performance of the students in the tasks. It is observed that there is no wide deviation in the aspects of the spoken components with respect to their performance in the tasks. If the students were able to generate content cohesively, the other aspects like grammar, volume, pronunciation and fluency would be in place.

\subsection{Independent sample t-test for spoken components in post-task}

Independent sample t-test was computed to compare the mean scores of each speaking component in the post-task score of the control and experimental groups. The mean and standard deviation of the scores are tabulated in the table 9 .

Table 9. Independent samples t-test for spoken components in post-task

\begin{tabular}{lllllll}
\hline Test Component & Group & $\mathrm{N}$ & $\mathrm{M}$ & $\mathrm{S} . \mathrm{D}$ & $\mathrm{T}$ Value & $\mathrm{P}$ \\
\hline Fluency & Experimental & 38 & 2.28 & 0.60 & 7.45 & 0.01 \\
& Control & 38 & 1.13 & 0.73 & & \\
Grammar & Experimental & 38 & 0.96 & 0.21 & 10.17 & 0.01 \\
& Control & 38 & 0.42 & 0.24 & & \\
Idea/Content & Experimental & 38 & 0.72 & 0.25 & 5.16 & 0.01 \\
\multirow{2}{*}{ Volume } & Control & 38 & 0.41 & 0.28 & & \\
& Experimental & 38 & 0.89 & 0.24 & 6.00 & 0.01 \\
Pronunciation & Control & 38 & 0.50 & 0.33 & & 0.01 \\
& Experimental & 38 & 0.74 & 0.25 & 6.08 & \\
Total & Control & 38 & 0.39 & 0.24 & & 0.01 \\
& Experimental & 38 & 5.63 & 1.13 & 8.46 & \\
\hline
\end{tabular}

${ }^{*} \mathrm{M}=$ Mean, ${ }^{* * \mathrm{SD}}=$ Standard Deviation

The above table reveals that there is a substantial difference between the control and experimental groups in the post-task score in terms of fluency, grammatical ability, idea/content, volume, pronunciation and total score $(p<0.01)$. It is obvious that experimental group has shown considerable improvement over the control group. The table explicitly indicates that the implementation of oral communicative tasks has proved to have developed the speaking ability of the experimental group and helped the group to overcome the speaking constraints. The mean scores of both groups' performance in post-task are vividly depicted for better comprehension in the figure below (see Figure 1). 


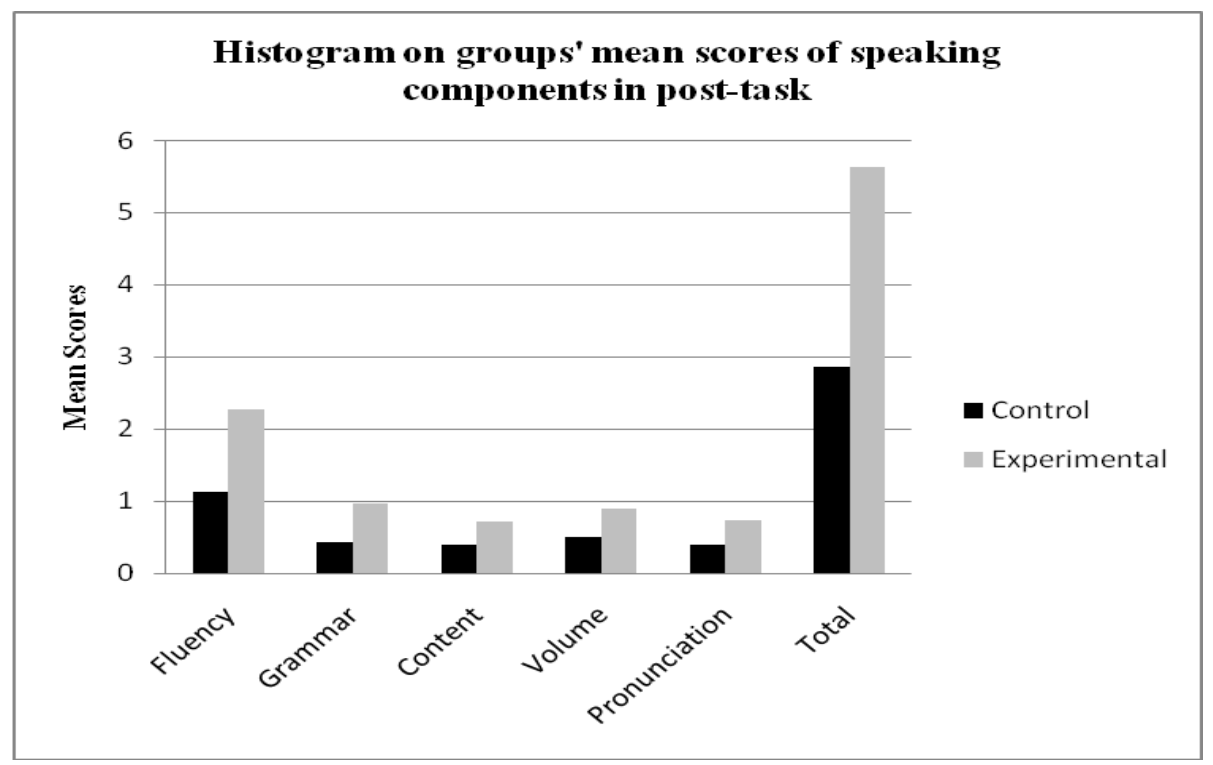

Figure 1. Results of Comparison of Speaking Components

Figure 1 indicates that the experimental group had performed better than the control group in the post-task components based on the analytic parameters of the CEFR. Therefore it can be concluded that the experimental group outperformed the control group in their speaking proficiency.

\section{Discussion}

\subsection{Research question 1}

The experimental group faced many constraints while performing the OCT. Majority of the participants were first time speakers and were affected by their fear of failure. The stage fear prevented them from speaking and comprehending the prompting cues. Aydin (2008) investigated the source and levels of fear of negative evaluation and language anxiety among Turkish EFL learners. The result indicated that fear of negative evaluation itself to be a source of language anxiety. Ozturk and Gurbuz (2014) examined the determining factors of speaking anxiety in Turkish EFL context and found that pronunciation, immediate questions, fear of making mistakes and negative evaluation as the major cause of EFL speaking anxiety. The participants of this study also were perplexed with this kind of speaking anxiety. The students could not practice and prepare for the tasks in the home environment due to incompatible sociolinguistic atmosphere, and their inability to generate sentences in English on their own.

Many found it difficult to convey a message or an idea. They seemed to be lacking in discourse ability of organizing thoughts. This was explicit when learners could not express themselves cohesively relevant to the context. This was found to be a major impediment in their oral proficiency. They either produced half sentences in their speech or had false starts. They were unable to speak clearly, and their voice level reduced due to their shyness, inhibition and lack of confidence. Few had L1 
interference in their speech. Some of them mumbled, left unnecessary and unnatural pauses in their speech, as they searched for the right word. Some used fillers like, aaah, uumm, and, I, etc. The teacher focused on enabling the students to organize their thoughts, form logical progression of ideas and then the teacher focused on improving the delivery mechanism.

Many learners had poor vocabulary and lack of knowledge in grammar. The inappropriate words and incorrect sentences reflected their shortcomings in the task performance. They mispronounced the words in their presentation. Similarly, TokozGoktepe (2014) inquired the speaking problems of ninth-grade high school Turkish EFL learners and found that the students' problems in speaking English were mainly due to insufficient language and content knowledge, limited contact with English outside the classroom, and the misdirected methods and materials used in the classroom.

Students' resistance to participate in oral communicative tasks was noted as another significant limitation. Some students avoided eye contact with the audience in their participation and kept their face down. They had lack of motivation to carry out certain tasks. They had no idea of performing an individual extemporaneous task. Moreover, their speaking constraints were due to their lack of exposure in the second language. Most of the learners were habituated to read academic texts in the L2. Hence the students' language was restricted to fixed diction and sentence structures pertaining to their academic context. The teacher enabled the learners to use learner strategies to overcome the constraints they faced in their task performance. They wrote in mother tongue, and approached the facilitator for L2 equivalent. They also elicited cues from their peers' speech and incorporated in their content knowledge use. They learnt to make intelligent guesses and used contextual clues in comprehension (Rubin \& Thompson, 1982, as cited in Brown 2001: 132-133).

\subsection{Research question 2}

The factors affecting the speaking skills of ESL learners can be broadly categorized into four as: psychological, pedagogical, linguistic and sociological (Shanmugasundaram, 2013). The language proficiency of the participants varied as majority of them were from regional medium schools and others from English medium schools. Even the English medium students lacked expected language proficiency due to lack of exposure. From their body language and facial expressions it was evident that the students (participants) had high level of anxiety. For instance they were initially hesitant and reluctant to perform the tasks. MacIntyr and Gardner (1991) emphasize that the feeling of anxiety can cause many problems in the acquisition, retention and production of language. The students struggled with speaking English as their anxiety led to unintended problems such as fear of speaking in front of all, not being understood by others and inferiority problems. Discouragement by friends /peers seems to be a dominant factor in the study. As Jianing (2007) explains in her work "To protect themselves from being laughed at, the students are reluctant to 
speak English....the less they speak, the less they improve their speaking skills, and the more they are afraid of speaking" (p.1), the students had fear of being insulted or teased when they tried to open a conversation in English with friends. Most of the students seemed to have inferiority complex. The students who hailed from Tamil medium schooling believed that they could not learn to speak in English, and it was possible only for English medium students. Besides at the sociological level, their home atmosphere was not congenial and helpful in practicing L2. The attitude of some students was not positive towards learning English. Furthermore, many had constraints at the linguistic level, such as lack of coherence in their utterance, problems in pronunciation, lack of vocabulary, lack of knowledge in grammar etc. Liu and Jackson (2009) claimed in their study that lack of vocabulary was regarded as a predominant impediment for spoken communication by Chinese English learners. In this study too, the participants considered their inadequacy in vocabulary as prevalent obstacle in their task performance. The factors that come under pedagogical level which affect the speaking skill of the learners are the teaching and learning methods practiced in their schools viz.., teachers' use of mother tongue in English classroom, absence of interactive sessions in English and lack of exposure etc. Although the importance of spoken proficiency in English was felt by the students, they seemed to be lacking interest in executing speaking activities as they would not be assessed in the end semester. They wanted to concentrate more time on examoriented exercises.

\subsection{Research question 3}

The teacher's role is instrumental in training the students in OCT classes to attain L2 oral proficiency. The researcher applied the strategies specified in Dornyei (2001) in implementing the tasks. The facilitator demonstrated the tasks to the students and consistently showed personal interest in developing their speaking proficiency in English. She promoted the development of group cohesiveness and associated slow learners with their enthusiastic peers in the task on listing of five to do's. She cultivated their interest in L2 learning and explained the utility of L2 in the real-life situations. The facilitator made learning more pleasant and provided positive feedback throughout the sessions (Dornyei, 2001). The facilitator subdued their psychological barriers by providing motivation, encouragement and maintaining conducive classroom environment. The classroom turned to be a learner-centered classroom, a kind of classroom in which the focus is on the active involvement of learners in the learning process. The teacher organized demonstrative sessions on tasks such as discussing similarities and differences to enhance the understanding of tasks by the learners and to subdue their impediments such as their fears and inhibitions. The teacher overcame the linguistic constraints of the students through her interactive classes and feedback sessions. The teacher assured that all the students would be given equal opportunity. Dornyei (2001) states that the teacher needs to understand the learners' needs and goals, communicate trust and respect for them, acknowledge their different needs and learning style, and give feedback on 
their learning and all these would help in developing their confidence and selfesteem.

The researcher cum facilitator in this study encouraged the students and motivated them to participate in the tasks. The students were made to interact with their peers in role play tasks to overcome their constraints in speaking performance. Their participation increased their confidence level to make oral presentation. Benson (2001) indicates that learner-centered teaching is effective in generating more student participation and target language output and also in encouraging students to take more personal responsibility for their learning. Yet some of the slow learners felt inhibited to participate in the class interaction in initial task on listing 10 activities of given professionals and the facilitator paired them with enthusiastic high performance learners and shared the challenging tasks. The slow learners started to acquire the nuances of delivering content with logical progression of ideas. The facilitator enabled them to select the right word, structure a sentence, suggest an alternative word, and correct an ill-constructed sentence or their mispronunciation. The facilitator also helped the students to think in English. The learners were made to read aloud to overcome their pronunciation problems. In the due course, the facilitator enabled the students to overcome the barriers and volunteer in taking up the tasks. During the oral communicative tasks, the comments and feedback provided by both the peers and the facilitator helped the students to perform better in the subsequent oral tasks. The facilitator motivated the learners by making them work in pairs and groups and act as an audience. Majority of the students aspired for more number of OCT sessions that exhibits their interest in this interactive learning environment. Edge (1989) states teachers' feedback should encourage students' learning steps and pointing out the error would be too negative. The teacher never failed to appreciate the smallest effort made by the learners in the task performance. Students were the center of the learning process and were enabled to share more responsibilities in their learning of speaking skills. In this line, they were given opportunities to improve their working knowledge in English, and in turn become independent speakers. This brings about decisive change in the teacher's role from an authoritarian to a facilitator, organizer, helper, and language adviser. This is consistent with the study of Mohammadipour and Rashid (2015).

\subsection{Research question 4}

Cluster analysis which was based on the students' motivation level, performance, and enthusiasm, was computed to interpret their improvement from pre to post-task. Four clusters were arrived based on their improvement percentage and named as, high level of improvement, above average, average, low level of improvement. 
Table 10. Improvement level of students in four clusters

\begin{tabular}{llcc}
\hline Cluster No. & Name of the category & Percentage of improvement & No. of students \\
\hline Cluster-1 & High level of improvement & $100 \%-83 \%$ & 4 \\
Cluster-2 & Above average & $71 \%-55 \%$ & 7 \\
Cluster-3 & Average & $50 \%-37.5 \%$ & 12 \\
Cluster-4 & Low level of improvement & $33 \%-18 \%$ & 15 \\
& & \\
\hline
\end{tabular}

As the table shows a considerable number of students fall in the first 3 cluster namely, high level, above average, and average. Out of 38 students in the class, a substantial number of students $(n=23)$ have shown improvement in their spoken proficiency after attempting the oral communicative tasks. Even in cluster-4 of low level improvement, 8 students were sustaining better performance in all the tasks. In the high level of improvement cluster, the students' motivation level was high, and they participated in all the activities. They gradually progressed in their oral performance. Though they found it difficult to perform the tasks initially, they tried with the help of the facilitator and their peers. Participant 23 in the beginning could not speak clearly due to lack of vocabulary and grammatical knowledge. But her motivation level was high that she concentrated working on the tips given by the facilitator towards her progress. She never hesitated to seek the facilitator's help in performing the activities. In the above average cluster, Participant 2, Participant 9, Participant 15, and Participant 16 performed well in the later activities. They looked forward to the OCT sessions and felt the need to improve their language proficiency. They worked for their progress and approached the facilitator to select a right word, or structure a sentence, or grammar correction.

In the average cluster, the participants were highly inhibited and shy. Even those who were proficient enough to speak English, felt hesitant to take part in the classroom activities. Some of them were bold enough to take part in the oral communicative tasks, but they were inadequate in vocabulary and grammar. Despite the efforts of the facilitator, they slowed down in their progress. They could not show steady improvement, as they had some difficulty in constructing sentences and expressing their thoughts.

The low level of improvement cluster has two different levels of students - the better performers in the pre-task, who felt that the task-1 of listing out activities of given profession was monotonous as they were not patient to listen to their peers' performance and the other group of students who were reticent, did not involve in the activities due to their lack of proficiency. The proficient participants were well ahead of others in performing the tasks and moreover they took part in all the tasks as well. The reticent students were reluctant and disinclined to participate in the oral communicative tasks. When they were compelled to perform activities, they were resistant and undemonstrative. They seemed to be uncomfortable throughout the session and absented themselves deliberately for some sessions. Peloghities (2006) states that real-life interactions, a significant factor for second language acquisition 
"demand a great deal of spontaneity and the ability to cope with the unexpected" (p.48).It was taken into account that practicing OCT in the class would benefit the participants to use English in real situations as the interactions that happened in the classroom is a simulation of a real life activity. Willis (1996) indicates, "tasks are always activities where the target language is used by the learner for a communicative purpose (goal) in order to achieve an outcome” (p. 23). The OCT employed in this study proved to be effective in improving the speaking proficiency of the experimental group.

\section{Conclusion}

This study was an attempt to improve the engineering students' spoken proficiency using oral communicative tasks. The OCT was implemented in a regular classroom atmosphere by observing and noting their impediments in speaking, recording students' progress, interacting and reflecting on various aspects of tasks and students' outcomes. The findings were drawn from the OCT performance of the participants, their constraints in speaking, the affective factors, and the pedagogical intervention which attempted to enable the students overcome their constraints in their speaking skill. The assigned tasks brought real life situations into the class, where students were provided opportunities to express their ideas and exchange their opinions. The students could express their ideas freely because they performed the activities in pairs and groups with their friends and the classroom had become more of a learnercentered environment. The study found that freedom of task selection encouraged the participants to feel comfortable and motivated to speak, and definitely minimized their constraints in speaking.

In the light of above discussion, it can be concluded that the constraints in speaking can be subdued and speaking proficiency of the engineering students can be developed using oral communicative tasks in the classroom. It is agreed that TBLT is particularly effective in breaking the barriers in speaking and enhancing the speaking proficiency of the learners when they are engaged in relatively similar real-life tasks. The factors affecting the constraints in speaking skills were addressed in this study. The effectiveness of the tasks implemented made the students realize their pitfalls in oral communication and improve their speaking proficiency. The result of the present study proved that $61 \%$ of the students had shown considerable improvement. In the experimental group of 38 students, 23 members participated in the oral tasks with involvement. The results clearly indicated that the students became aware of their constraints and improve their speaking skills gradually by involving them in oral communicative tasks. This study addressed one of the long ongoing issues of improving the speaking proficiency of the engineering graduates in the era of globalization. This experimental study explicitly indicates that the speaking proficiency of the students can be improved by devising OCT, and it also draws English teachers' attention towards their vital role of improving language proficiency of their learners in ESL context. Finally and perhaps most importantly it is suggested to undertake longitudinal study to obtain substantial results in future studies. The 
cognitive and metacognitive strategies could be devised for rectifying learner constraints in their oral communicative tasks.

\section{Limitations}

The researcher found less contact hours as the limitation of the study. The need to cover the syllabus and to keep pace with the rest of the topics/ portions mentioned in their course plan and to prepare the students for their periodical tests were to be considered. The researcher was also the observer in this study, she focused on improving the speaking proficiency of the experimental group by substituting an alternative for the inappropriate usage of word, or correcting an ill-constructed sentence rather than quantifying the errors. If there had been a separate observer, he/she would have quantified the list of constraints. In this study, the researcher focused on rectifying the constraints such as false starts, fillers, long pauses, mispronunciation, mother tongue usage, grammatical errors and helping the learners to overcome them in their task performance. It is also pertinent to note that errors were not persistent in the case of majority of the learners.

\section{References}

Aydin, S. (2008). An investigation on the language anxiety and fear of negative evaluation among Turkish EFL learners. Online Submission. Retrieved from http://files.eric.ed.gov/fulltext/ED512266.pdf

Benson, P. (2001). Teaching and Researching Autonomy in Language Learning. London: Longman.

Brown, H.D. (2001). Teaching by Principles. An Interactive Approach to Language Pedagogy. Englewood Cliffs: Prentice Hall.

Bygate, M. (1987). Speaking. Oxford: Oxford University Press.

Council of Europe (2001). Common European Frame work of References for languages: Learning, Teaching, Assessment. Cambridge: Cambridge University Press.

Dörnyei, Z. (2001). Motivational Strategies in the Language Classroom. Cambridge: Cambridge University Press. DOI: http://dx.doi.org/10.1017/CBO9780511667343

Edge, J. (1989). Mistakes and Correction. Longman Keys to Language Teaching. Harlow: Longman.

Ellis, R. (2002). The evaluation of Communicative Tasks. In B. Tomlinson (Ed.), Materials Development in Language Teaching. Cambridge: Cambridge University Press. 217-238.

Ellis, R. (2003) Task-based Language Learning and Teaching. Oxford: Oxford University Press.

Harmer, J. (2007). How to Teach English-New edition. Harlow: Pearson Education Limited.

Horwitz, E. K., Horwitz, M. B., \& Cope, J. (1986). Foreign language classroom anxiety. The Modern Language Journal, 70(2), 125-132.

Jamila , M. (2013). Use of Learner Autonomy in Teaching Speaking by Tertiary Level English Language Teachers in Private Universities of Bangladesh. IOSR Journal Of Humanities and Social Science, 18(4), 29-43.

Jianing, X. (2007). Storytelling in the EFL Speaking Classroom. The Internet TESL Journal, 13(11), Retrieved on April 10, 2010 from www.iteslj.org.

Juhana. (2012). Linguistic Factors that Become Students' Obstacles to Speak in English Class. Journal of Education and Practice, 3(12), Retrieved on 25.10.2016 from www.iiste.org.

Kothari, C.R. (2004). Research Methodology: Methods and Techniques. New Age International: New Delhi. 
Liu, M. \& Jackson, J. (2009). Reticence in Chinese EFL students at varied proficiency levels. TESL Canada Journal, 26(2), 65-81.

Long, M. H. \& Crookes, G. (1992). Three approaches to Task-based syllabus design. TESOL Quarterly, 26(1), 27- 55.

MacIntyer, P.D. \& Gardner, R.C.(1991). Language anxiety. Its relationship to other anxieties and to processing in native and second languages. Language Learning, 41, 513-534.

Mohammadipour, M. \& Rashid, S. (2015). The impact of task-based instruction program on fostering ESL learners' speaking ability: A cognitive approach. Advances in Language and Literary Studies, 6(2).

Nunan, D. (1988). Syllabus Design. Oxford: Oxford University Press.

Nunan, D.(1991a). Language Teaching Methodology. London: Prentice Hall International.

Nunan, D. (1991b). Communicative tasks and the language curriculum. TESOL Quarterly, 15(2), 279- 295.

Nunan, D. (1999). Second Language Teaching \& Learning. Heinle \& Heinle Publishers.

Öztürk, G., \& Gürbüz, N. (2014). Speaking anxiety among Turkish EFL learners: The case at a state university. Journal of Language and Linguistic Studies, 10(1), 1-17. Retrieved from http://jlls.org/index.php/jlls/article/viewFile/178/165

Only 18\% engineering grads are employable, says survey. (2014, July 16). The Times of India. Retrieved from http://timesofindia.indiatimes.com/city/mumbai/Only-18engineering-grads-are-employable-says-survey/articleshow/38438996.cms

Peloghitis, J. (2006). Enhancing communication through the use of foreigner interviews. Journal of NELTA, 11(1-2), 47-51.

Prabhu, N .S. (1987). Second Language Pedagogy. Oxford: Oxford University Press.

Reimer, M.J. (2007). Communication Skills for the 21st Century Engineer. Global Journal of Engineering Education, 11(1), 89-100.

Shanmugasundaram, S.(2013). Factors Affecting the Spoken English of Tertiary Level Students from Arts and Science Colleges in the District of Tiruchirapalli and ThanjavurA Study, PhD Thesis, Department of Humanities, NITT.

Thornbury, S. (2005). How to Teach speaking. Harlow, England: Longman.

Tokoz-Goktepe, F. (2014). Speaking problems of 9th grade high school Turkish learners of L2 English and possible reasons for those problems: Exploring the teachers and students' perspectives. Procedia-Social and Behavioral Sciences, 116, 1875-1879. Retrieved from http://www.sciencedirect.com/science/article/pii/S1877042814005047

Ur, P. (1995). A Course in Language Teaching. Practice and Theory. Cambridge: Cambridge University Press.

Van Le, T. (2014). Factors Affecting Task-Based Language Teaching from Teachers' Perspectives. Study in English Language Teaching, 2(1) 108-122.

Willis, J. (1996). A Framework for Task-Based Learning. Harlow, Essex: Addison Wesley Longman. Longman.

Zaremba, A. J. (2006). Speaking Professionally. Canada: Thompson South-Western.

\section{Copyrights}

Copyright for this article is retained by the author(s), with first publication rights granted to the Journal.

This is an open-access article distributed under the terms and conditions of the Creative Commons Attribution license (CC BY-NC-ND) (http://creativecommons.org/licenses/by-nc-nd/4.0/). 